\title{
Who wants a big gun, and why?
}

The discovery of components for a huge gun apparently being assembled in Iraq has caused a sensation, and has stimulated endless speculation about its nature. Here is some more.

Could there be a connection between the discovery, at London airport three weeks ago, of capacitors designed for triggering nuclear explosions and the way in which components of a huge gun bound for Iraq have come to light at British and Greek ports in the past few days? Could the triggering devices have been intended not for use with nuclear explosives but, rather, to detonate explosive charges at intermediate points along an overlong gun barrel? What follows is almost entirely speculation, but may go some way to illuminate some of the melodrama of the past few weeks.

The circumstances are these. Ten days ago, British Customs and Excise impounded four massive steel tubes at a British port, announcing that they were sections of a gun barrel. It has since come to light that the manufacturers, in Sheffield, had made a total of 16 tubes of the same design, most of which had already been shipped to Iraq. Initial scepticism of the customs' claim has been exorcised by the discovery last weekend, at the Greek port of Patras, of what seems to be part of the breech mechanism of a huge gun, the barrel of which is reckoned to be more than 160 metres long. Curiously, the device was bound for Iraq on the platform of an open truck.

Those who know about artillery design say that such a barrel is inexplicable on conventional grounds. The most effective high-velocity weapons now in service, notably the South African long-range gun, are built with barrels some 45 times longer than the diameter of the projectiles they are designed to fire. Previous generations of weapons have worked with smaller ratios of barrel-length to calibre -40 or even less.

That there should be some such limit is understandable. The function of a gun barrel is to allow the continued acceleration of the projectile by the shock-wave from the propellant charge and eventually from simple hydrostatic pressure, which must diminish along the length of the barrel. Plainly there will be a point at which friction between projectile and barrel will be greater than the decreased propellant pressure, at which point the barrel might usefully be terminated.

Moreover, there are also limits to what can be done by increasing the propellant charge; the breech mechanism has to be more robust, but the propagation of a detonation in the solid propellant may be so much slower than that of shock-waves along the barrel that extra propellant simply goes to waste.

Apparently, the optimum ratio of barrel length to calibre is determined empirically to be roughly constant, yielding a maximum muzzle velocity and thus range, in practice roughly $600 \mathrm{~m} \mathrm{~s}^{-1}$ and $40 \mathrm{~km}$ respectively. (The use of undersized projectiles allows the terminal velocity to be increased, but uneconomically.) The ideal characteristics of the propellant naturally vary with the mass of the projectile. But why should Iraq be bent on building a gun with an over-long barrel? Even with an internal diameter of 1 metre, a barrel $40 \mathrm{~m}$ long should give the longest range.

One explanation is that Iraq planned to build a gun in which the muzzle velocity of the projectile would be increased by replenishing the supply of propellant gases at intervals along the length of the barrel. Apparently this has been tried before in the German project, during the Second World War, for building a gun capable of reaching London from the coast of the mainland. Experience seems to have shown that one firing in three caused the gun barrel to explode. It is easily appreciated that the failure of that project may have sprung from the difficulty of timing the explosion of the intermediate propellant charges with sufficient accuracy. The amount of the intermediate charge is important, but the timing of its detonation immediately on the heels of the passing projectile must be crucial.

That is where the detonating capacitors impounded at London Airport earlier in the month may be relevant. It is neither here nor there that the real goods had been replaced by fakes by collaboration between the US and British intelligence agencies - the originals must have been intended for the accurate timing of explosions of some kind. In the Iraqi experiment, if that is what it was, the ideal would be that each section of the gun barrel would be joined to its successor by a short section carrying a cylindrical explosive charge, which would allow of 15 intermediate explosions. It will be interesting to see whether manufacturers in the West have been making to the order of Iraqi agencies cylindrical steel sections of $1 \mathrm{~m}$ internal diameter with concentric chambers for carrying internal propellant charges.

Would such an arrangement suffice to give the Iraqi gun a range significant in the Middle East? Because the range of a gun (neglecting atmospheric resistance) is roughly proportional to the square of the muzzle velocity, the auguries are good, but increasing the range from $40 \mathrm{~km}$ to, say, $400 \mathrm{~km}$ would require that the muzzle velocity should be increased more than threefold, which is a tall order. Would that be feasible?

Given the complexity of what happens in a gun-barrel, there seems little future in attempts at precise calculation, but a little handwaving may not be inappropriate. The sections of steel tubing impounded by the British authorities all have the same wall diameter (more than $20 \mathrm{~cm}$ ). Assuming, conservatively, that half the acceleration of the projectile is normally brought about in the first quarter of the barrel, any means of renewing the initial shock wave one quarter of the way along would add to the terminal velocity. And so on, at repeated intervals along the length.

But not pro rata. At successive intermediate intervals along the barrel, the relative velocity of the shock-waves from intermediate propellant charges would be reduced, and so would be the efficiency with which momentum is transferred from the gases to the projectile. Again there will be a limiting muzzle velocity - the efficiency of the process will decline to zero when the shock wave cannot catch the accelerated projectile. That limit, a function of the density of gases in the barrel and of their composition, could easily allow the terminal velocity of $600 \mathrm{~m}$ $\mathrm{s}^{-1}$ to be exceeded four-fold after 15 intermediate renewals of the shock-wave.

Whether that was really what Iraq was about will probably remain publicly unknown. The originator of the project seems to have been a Dr Gerald Bull, of Canadian origin but with US citizenship, who was murdered by gunmen outside his Brussels apartment three weeks ago. Bull's company, International Space Systems, seems to have placed contracts for the gun components with their British manufacturers. Previously, he had been the driving force for the joint US-Canadian 'HARP' project for sending rocketassisted projectiles high into the atmosphere and even into orbit and for the development of the South African artillery piece.

Bull's competitors in the arms trade have a great respect for his ingenuity; one said on the telephone this week that "if Gerry said it could be done, I'd believe him and not the others". But the general opinion seems to be that Bull was more interested in gun-launched rockets and in undersized projectiles than in more complicated devices. On this occasion, time may not tell.

John Maddox 